\title{
Exploring damping characteristics of composite tower of cable-stayed bridges
}

\author{
SHEHATA E ABDEL RAHEEM ${ }^{1 *, 2}$ (1) \\ ${ }^{1}$ Faculty of Engineering, Civil Engineering Department, Taibah University, Madinah 41411, P.O. 344, Saudia Arabia \\ ${ }^{2}$ Faculty of Engineering, Civil Engineering Department, Assiut University, Assiut 71516, Egypt \\ e-mail: shehataraheem@yahoo.com
}

MS received 3 March 2015; accepted 26 September 2015

\begin{abstract}
The damping characterization is important in making accurate predictions of the seismic response of the hybrid structures dominated by different damping mechanisms. Different damping characteristics arise from the construction of the tower with different materials: steel for the upper part; reinforced concrete for the lower main part and interaction with supporting soil. The process of modeling damping matrices and experimental verification is challenging because damping cannot be determined via static tests as mass and stiffness can be. The assumption of classical damping is not appropriate if the system to be analyzed consists of two or more parts with significantly different levels of damping. The dynamic response of structures is critically determined by the damping mechanisms, and its value is very important for the design and analysis of vibrating structures. An analytical approach that is capable of evaluating the equivalent modal damping ratio from structural components is desirable for improving seismic design. Two approaches are considered to define and investigate dynamic characteristics of a composite tower of cable-stayed bridges: The first approach makes use of a simplified approximation of two lumped masses to investigate the structure irregularity effects including damping of different material, mass ratio, frequency ratio on dynamic characteristics and modal damping. The second approach employs a detailed numerical step-by-step integration procedure.
\end{abstract}

Keywords. Structural vibration; damping characteristics; composite tower; modal damping.

\section{Introduction}

As demonstrated by many field forced-excitation tests, the damping characteristics of hybrid cable-stayed bridges vary from a bridge to another. This is due to the fact that the energy mechanisms predominant in the bridges are different. Therefore an analytical approach that is capable of evaluating the equivalent modal damping ratio of cable-stayed bridges from structural components is desirable to improve the seismic design [1-7] by dividing the cable-stayed bridge into several substructures in which the energy dissipation mechanisms can be regarded as the same, it is proposed for each substructure to evaluate the energy dissipation function, which relates the amount of energy dissipation, with either the strain energy or the displacement at specific points in the substructures. In code-based seismic design of such hybrid structures several practical difficulties are encountered, due to inherent differences in the nature of damping of different parts. Such structures are irregularly damped and have complex modes of vibration, so that their analysis cannot be handled with readily available commercial software. Studies of dynamic characterization are extremely important in formulating predictive models for seismic response of hybrid cable-stayed bridge structures subjected to earthquake loadings [8-10]. Characterization of damping forces in a vibrating structure has long been an active area of research in structural dynamics [5, 6, 11-18]. There are many situations in which the un-damped and classically damped assumptions are invalid. Examples of such cases are the structures made up of materials with different damping characteristics in different parts, structures equipped with passive and active control systems and structures with layers of damping materials [19].

The process of modeling damping matrices and their experimental verification is challenging because damping cannot be determined via static tests as mass and stiffness can be. Furthermore, damping is more difficult to determine from dynamic measurements than natural frequency. There have been detailed studies on the material damping [20] and also on energy dissipation mechanisms in the joints [21]. But here difficulty lies in representing all these tiny mechanisms in different parts of the structure in unified manner. The performance of a classical damping matrix, constructed either from the use of initial structural properties or current structural properties, in the step-by-step solution of a nonlinear multiple degree of freedom system is analytically evaluated [22]. However, in most real systems the damping is non-classical, even when classical damping is assumed 
for each sub-system in the analysis of mixed steel/concrete structure-soil interaction systems. In such problems, a more realistic model for the damping force should be used to capture the correct response, which leads to complex Eigen properties [23]. Moreover, the damping matrix is required for most of standard analysis methods for a complete system. The seismic response of non-classical damping systems can be substituted approximately by the seismic response calculated according to uniform damping ratio of a concrete tower and a steel stiffening girder respectively, which can simplify the calculation during the preliminary analysis [24]. The equivalent damping could be approximately estimated with different methods, such as the complex modal analysis, neglecting off-diagonal-elements in modal damping matrix, composite damping rule.

In composite damping rule method; the equivalent damping ratio is computed as the sum of the damping ratio of each component weighted by the modal strain energy ratio of each component to that of the total bridge system $[1,7,25$, 26]. Papageorgiou \& Gantes [27, 28] proposed equivalent modal/uniform damping ratios for structures with Rayleigh type damping and with simpler damping configurations. The basis of these works is a trial and error process of potential uniform damping ratios in substitution of the actual damping distribution of the structure. Villaverde [29] proposed a method for using the complex modes of irregularly damped structures in combination with response spectra in order to compute the maxima of the structural response. Warburton $\&$ Soni [30] proposed a parameter to assess the accuracy of the effective modal damping ratio that is computed by eliminating the off-diagonal elements of modal damping matrix.

The classical damping assumption is not appropriate if the system to be analyzed consists of two or more parts with significantly different levels of damping, although it may be reasonable for each region separately. The well separated different materials cause damping to be unevenly distributed for the complete bridge, known as non-classical damping [31]. In conventional analysis of hybrid structures, it is generally assumed that damping may be defined in terms of modal damping ratios for different types of substructures. One such example is the mixed steel/concrete structure soil system; where the equivalent damping ratio for the hybrid system would typically be much different [32, 33] (15-20\% for the soil region, 5-10\% for footing compared to $2-5 \%$ for the steel super-structure). It is shown that the effect of non-classical damping is significant in systems that have nearly tuned modes and sufficiently small values of modal mass ratios. An analytical approach that is capable of evaluating the equivalent modal damping ratio from structural components is desirable to improve the seismic design. Two approaches are considered to define and investigate dynamic characteristics of hybrid tower of cable-stayed bridges: the first approach makes use of a simplified approximation of two lumped masses to investigate the structure irregularity effects including damping of different material, mass ratio, frequency ratio on dynamic characteristics and modal damping; the second approach employs a detailed numerical step-by step integration procedure in which the damping matrices of the upper and the lower substructures are modeled with Rayleigh damping formulation.

\section{Theoretical approach}

\subsection{Dynamic equilibrium equation of motion and characteristic equation}

The dynamic equilibrium equation of motion for a structural system with $n$-degree of freedom (DOF) subject to ground motion excitation, whether classically or non-classically damped, can be expressed as follows:

$$
\mathbf{M} \ddot{u}+\mathbf{C} \dot{u}+\mathbf{K} u=-\mathbf{M} r \ddot{u}_{g} .
$$

In which $\mathbf{M}$ and $\mathbf{K}$ are $n \times n$ mass and stiffness positive definite matrices, respectively. $\mathbf{C}$ is an $n \times n$ damping semipositive definite matrix; and $r$ is the dynamic load effect vector with all $n$ elements being 1 . The classical damping occur when the damping matrix is a linear combination of the mass and stiffness matrices. A commonly accepted scheme for the damping matrix $\mathbf{C}_{p}$ of classically damped systems is the Rayleigh's scheme, thus

$$
\mathbf{C}_{p}=\alpha \mathbf{M}+\beta \mathbf{K}
$$

where $\alpha$ and $\beta$ are real parameters, in formulating the Eigen value problem of the system and both sides of governing equation are pre-multiplied by $\mathbf{M}^{-1}$, which is also done with Eq. (2), to yield

$$
\mathbf{M}^{-1} \mathbf{C}_{p}=\alpha \mathbf{I}+\beta \mathbf{M}^{-1} \mathbf{K}
$$

Thereby making apparent the foregoing damping leads to a linear combination of what is known as identity matrix $\mathbf{I}$ and the dynamic matrix $\mathbf{M}^{-1} \mathbf{K}$. Therefore, matrices $\mathbf{M}^{-1}$ $\mathbf{C}_{p}$ and $\mathbf{M}^{-1} \mathbf{K}$ share the same set of eigenvectors, which explain why; the mathematical model can be decoupled under form (2). Indeed, adding a linear combination of powers of the dynamic matrix at the right hand side of Eq. (3) yields a new matrix that still shares the same eigenvectors with the dynamic matrix. Such generalization of the $\mathbf{C}_{p}$ matrix according to generalized damping scheme.

For both classically and non-classically damped structures; a coordinate transformation from physical coordinate's $u$ to modal coordinate's $q$ is adopted:

$$
u=\Phi q
$$

where $q$ is an $m \times 1$ generalized coordinate's vector (with $m \leq n)$, and $\Phi$ is the $n \times m$ modal matrix, normalized with respect to mass matrix and given by the solution of the undamped Eigen problem:

$$
\mathbf{K} \Phi=\mathbf{M} \Phi \Omega^{2}
$$

where $\Omega$ is a diagonal matrix listing the first $m$ few natural circular frequencies. By using Eq. (4), the differential 
equations of motion (1) in the modal sub-space can be written as follows:

$$
\ddot{\mathbf{q}}+\Xi \dot{\mathbf{q}}+\Omega^{2} \mathbf{q}=\mathbf{p} \ddot{u_{g}},
$$

where $\mathbf{p}$ is the vector of participation coefficients and $\Xi$ is the generalized damping matrix, given respectively by

$$
\mathbf{p}=-\Phi^{T} \mathbf{M} r, \quad \Xi=\Phi^{T} \mathbf{C} \Phi
$$

For non-classically damped systems, the matrix $\Xi$ is not diagonal. The relative maximum magnitude of the offdiagonal elements of $\Xi$ with respect to the diagonal elements can be expressed by the following coupling index [34, 35], which measures the degree of non-proportionality of the damping.

$$
\gamma=\max \left(\frac{\Xi_{i j}^{2}}{\Xi_{i i} \Xi_{j j}}\right) i \neq j
$$

\subsection{Eigenvalue problem by state-space approach}

The dynamic analysis of non-classically damped systems is one of the most important topics in the field of structural dynamics. In the dynamic analysis of structures, the Eigen value problem of the system should be solved a priori in order to avoid resonance or to define the natural vibration characteristics. By introducing the state vector $U$ [36], the equation of motion can be converted to a $2 n$-dimensional system of the first order differential equation given by

$$
\begin{aligned}
& \mathrm{A} \dot{U}+\mathrm{B} U=-F \bar{u}_{g} . \\
& \mathrm{A}=\left[\begin{array}{cc}
\mathrm{C} & \mathrm{M} \\
\mathrm{M} & 0
\end{array}\right], \mathrm{B}=\left[\begin{array}{cc}
\mathrm{K} & 0 \\
0 & -\mathrm{M}
\end{array}\right], \mathrm{F}=\left[\begin{array}{c}
\mathrm{M} r \\
0
\end{array}\right], U=\left\{u^{T} \dot{u}^{T}\right\}^{T} .
\end{aligned}
$$

The characteristic equation can be written as

$$
\left(\lambda_{j}^{2} M+\lambda_{j} C+K\right) \varphi_{j}=0 .
$$

Eq. (6) can be rearranged into state space form as

$$
\left[\begin{array}{cc}
0 & \mathrm{I} \\
-\mathrm{M}^{-1} \mathrm{~K} & -\mathrm{M}^{-1} \mathrm{C}
\end{array}\right]\left\{\begin{array}{c}
\varphi_{j} \\
\lambda_{j} \varphi_{j}
\end{array}\right\}=\lambda_{j}\left[\begin{array}{cc}
\mathrm{I} & 0 \\
0 & \mathrm{I}
\end{array}\right]\left\{\begin{array}{c}
\varphi_{j} \\
\lambda_{j} \varphi_{j}
\end{array}\right\}
$$

where $\lambda_{j}$ and $\varphi_{j}$ are the $j$ eigenvalue and the eigenvector of the structure system, respectively. The complex frequency has the form as

$$
\begin{gathered}
\lambda_{j}=-\alpha_{j} \pm i \beta_{j} \quad(j=1,2, \ldots m) \\
m: \text { number of vibration modes } .
\end{gathered}
$$

The equivalent modal frequency $w_{m j}$ and equivalent modal damping ratio $\zeta_{m j}$ of the complex frequencies are given as

$$
\begin{array}{r}
w_{m j}=\sqrt{\alpha_{j}^{z}+\beta_{j}^{z}}, \zeta_{m j}=\frac{\alpha_{j}}{w_{j}}(j=1,2, \ldots m) \\
m: \text { number of vibration modes } .
\end{array}
$$

The free vibration or natural modes of a non-classically damped system are to be distinguished from those of a corresponding system with classical damping by the fact that the components of the former modes differ in phase as well as amplitude. The effect of this variable phase on the motion of the system is that the motion is no longer characterized by the presence of fixed nodes as is the case for un-damped or classically damped systems. The nodes are no longer stationary but rather wander along the modal shape.

\section{Numerical results and discussion}

The structural behavior during an earthquake can be explained with the aid of modes of vibration of a structure. The major response in a system is primarily due to vibrations of its subsystems. The hybrid tower structure is composed of different substructures representing steel tower superstructure, reinforced concrete footing/pier and supporting soil. Different damping characteristics arise from the construction of the tower with different materials; steel for the upper part; reinforced concrete for the lower main part and supporting soil. Two approaches are considered to define and investigate dynamic characteristics of hybrid tower of cable-stayed bridges: the first approach makes use of a simplified approximation of two lumped masses to investigate the structure irregularity effects including damping of different materials, mass ratios and frequency ratios on the dynamic characteristics and modal damping while; the second approach employs a detailed numerical step-by step integration procedure in which the damping matrices of the upper and the lower substructures are modeled with the Rayleigh damping formulation.

\subsection{Simplified 2-DOF model}

An elementary analysis based on a simplified 2-DOF model "SDOF-SDOF coupled sub-systems", figure 1, representing a non-classically damped tower foundation soil interaction system is used to demonstrate the dynamic characteristics. The tower structure system of substructures with different

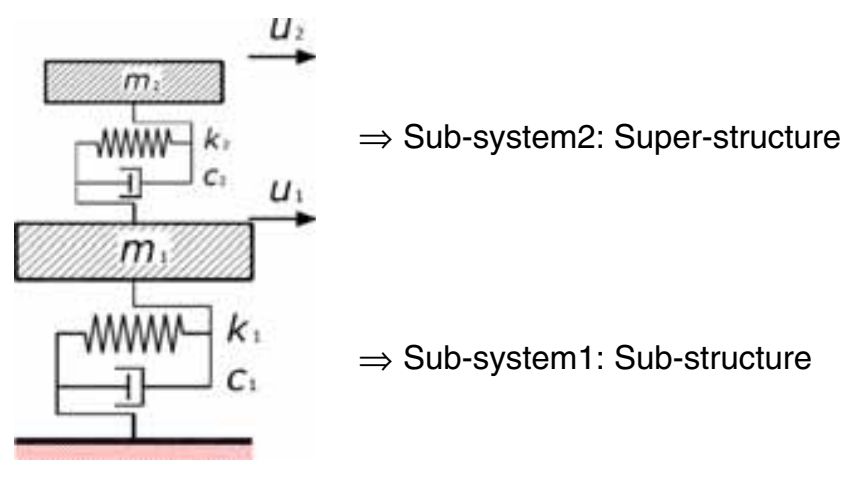

Figure 1. 2-DOF simplified tower model. 

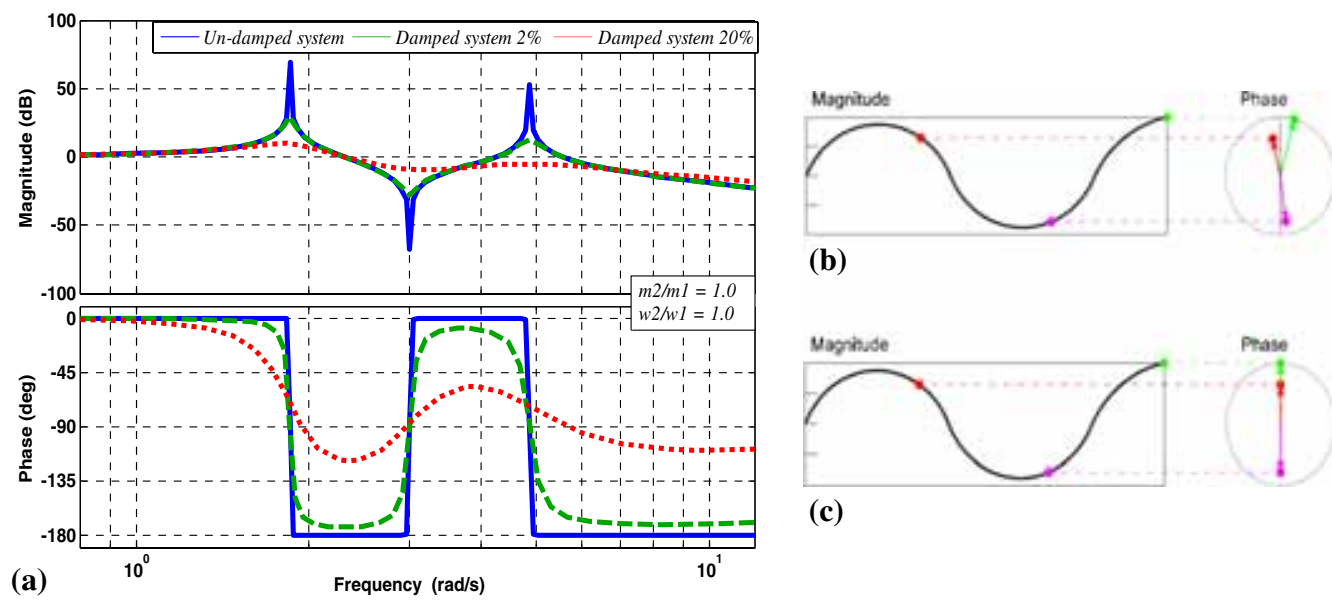

(b)

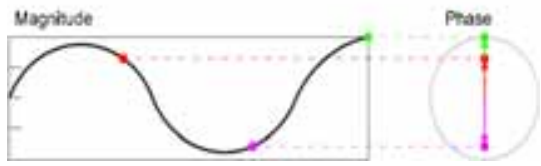

(c)

Figure 2. Damping effect on vibration modes: (a) frequency response function; (b) classical mode schematic; (c) non-classical mode schematic.

damping characteristics is represented by a simple model to study the effect of system structural parameters on the modal properties including the natural frequency, the modal damping characteristics, the damping matrix, the vibration mode shapes and the modal participation factor. The sub-systems modal parameters including the natural frequency and the damping ratio for each sub-system are given as follows:

$$
w_{j}=\sqrt{\frac{k_{j}}{m_{j}}}, \quad c_{j}=2 \zeta_{j} w_{j} m_{j} \quad(j=1,2) .
$$

The frequency domain approach is used to find the dynamic response characteristics. For systems with classical damping distributions, the phase angles between DOF's are always zero degrees (in-phase) or 180 degrees (completely out-of-phase) in each mode. The result is that, as time progresses, the shape (not the amplitude) of the free vibration response in a given mode shape remains constant. For systems with non-classical damping distributions, the phase angles generally lie between zero and 180 degrees and thus the DOF's are either in-phase or completely out-of-phase.
The result is that the shape of the free vibration response in a given mode shape changes with time. From the frequency response function plot shown in figure 2, the mass ratio $\left(m_{2} / m_{1}\right)$ and the frequency ratio $\left(w_{2} / w_{1}\right)$ are equal to unity for different levels of damping. It can be noticed that the amplitude of the peak response decreases significantly, which verifies the damping effects. The lower plot shows the phase relation between the base and the mass for different frequencies. At low frequencies, the phase is zero degrees, which means that the mass is in phase with the base. The phase becomes 90 degrees at resonance. At high frequencies, the phase is -180 degrees which means that; the mass is out of phase with the base and they move in opposite directions. For the non-classical damped system, the damping ratios affect the slope of the phase and the amplitude of the peak response.

The effect of the mass ratio $\left(m_{2} / m_{1}\right)$ and the frequency ratio $\left(w_{2} / w_{1}\right)$ on the acceleration frequency response function is investigated for equal damping ratios case $\left(\zeta_{1}=\right.$ $\left.\zeta_{2}=0.02\right)$ and different damping ratios of sub-systems $\left(\zeta_{1}=0.20, \zeta_{2}=0.02\right)$, as shown in figure 3. As the

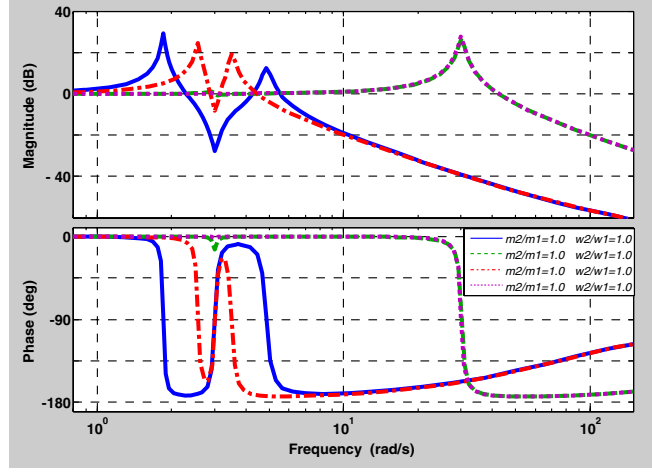

(a)

$\zeta_{1}=0.02, \zeta_{2}=0.02$

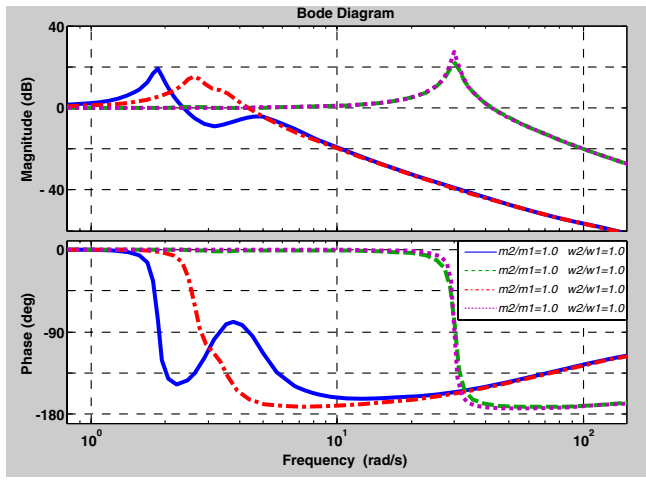

(b) $\zeta_{1}=0.20, \zeta_{2}=0.02$

Figure 3. Frequency response function. 
mass ratio decreases, the vibration modes get closer, the soft substructure dominant frequency increases, while the stiff substructure dominant frequency decreases. The lower mass ratio leads to significant modal coupling especially for equal dominant frequencies of substructures. Also a horizontal shift in the position of the natural frequencies is noted as the mass ratio increases. In a complex valued eigenvector, each element describes the relative magnitude and phase of the motion of the DOF associated with that element when the system is excited at that mode only. The relative position of each DOF can be out of phase by the amount indicated by the complex part of the mode shape element; all DOFs vibrate with the same phase angle if the mode shape is real-valued. For frequency domain analysis, the high damping lowers the resonant peak of a frequency response function. A further complication of large damping arises when natural frequencies are close, which is a common situation for high frequency modes in complex systems. In such situations, the modal bandwidth of adjacent resonant peaks might exceed the natural frequency difference, leading

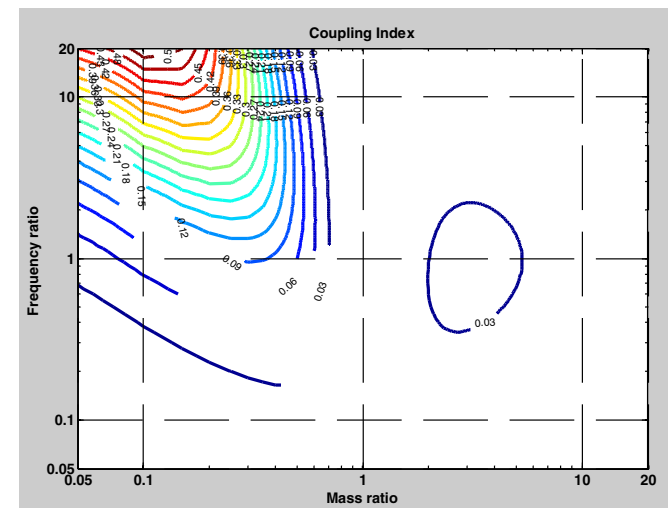

(a) $\zeta_{1}=\zeta_{2}=0.02$

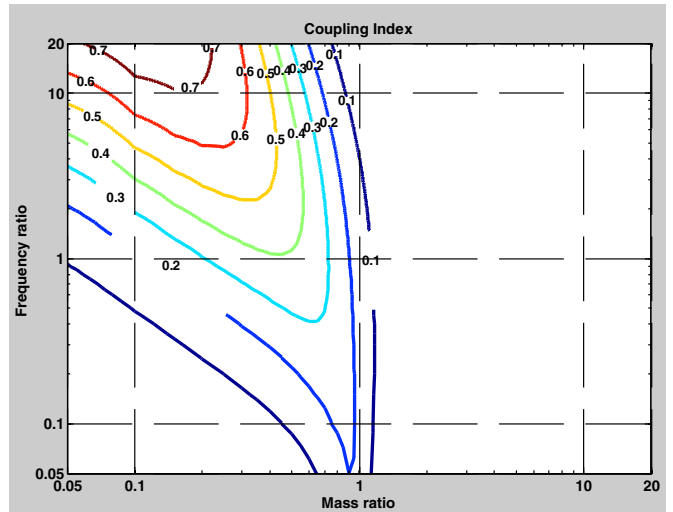

(b) $\zeta_{1}=0.02, \zeta_{2}=0.05$

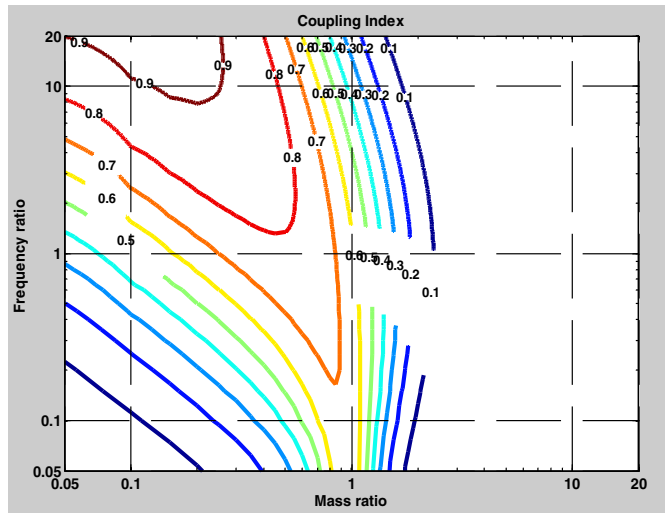

(d) $\zeta_{1}=0.02, \zeta_{2}=0.20$

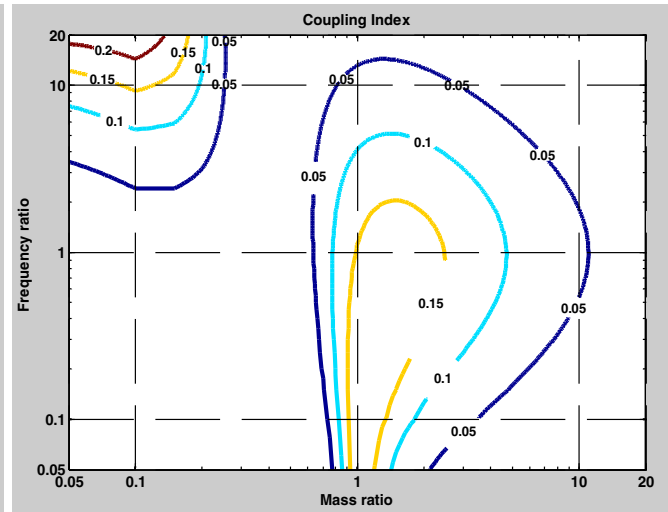

(c) $\zeta_{1}=0.05, \zeta_{2}=0.02$

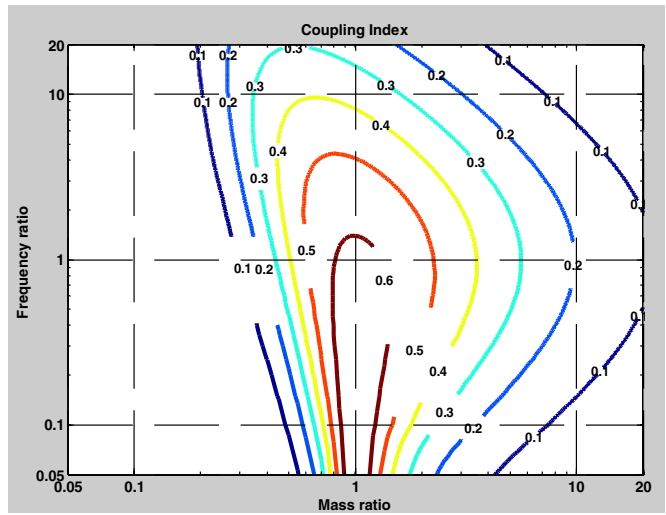

(e) $\zeta_{1}=0.20, \zeta_{2}=0.02$

Figure 4. Coupling index variation with mass/frequency ratio. 
to a merger of the resonant peaks into one broader peak, which is known as mode coupling. This can make it difficult to distinguish between the individual modes. It has been shown that the effect of non-classical damping is significant in systems with nearly tuned modes and sufficiently small values of modal mass ratios. The type of modes of a vibration would depend on the relative stiffness and the mass of different subsystems of tower structures, to cover a range of parameter variations including tower superstructure to footing structure frequency ratio; mass ratio, and different damping ratios for sub-systems. One of the major effects of non-classical damping on tower structures is to cause the damped modal vectors to be coupled with respect to the damping matrix, which is reflected mathematically by the non-zero off-diagonal elements in the transferred damping matrix and measured by the coupling index given by Eq. (8). Figure 4 shows the variation of coupling index with mass ratio $\left(m_{2} / m_{1}\right)$ and frequency ratio $\left(w_{2} / w_{1}\right)$ for uniform and different damping substructures. For sub-systems with uniform damping (almost classical damping scheme), the coupling index increases with structure irregularity as frequency ratio increases and the trend of increase becomes

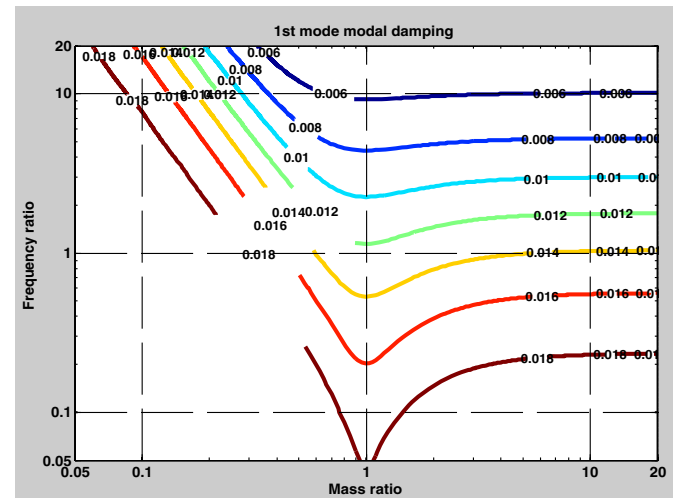

(a) $\zeta_{1}=\zeta_{2}=0.02$

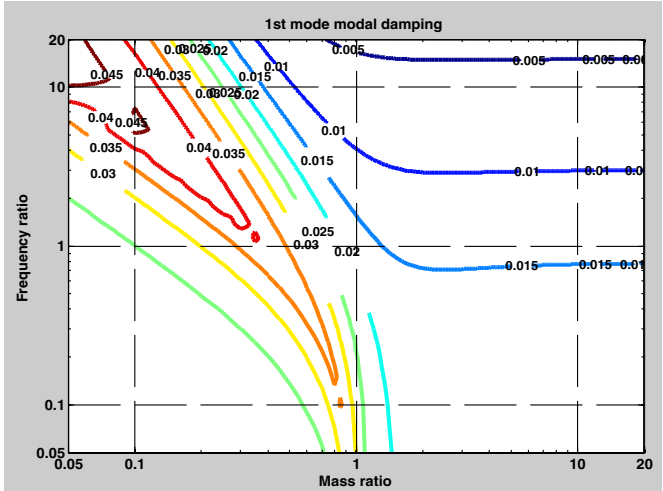

(b) $\zeta_{1}=0.02, \zeta_{2}=0.05$

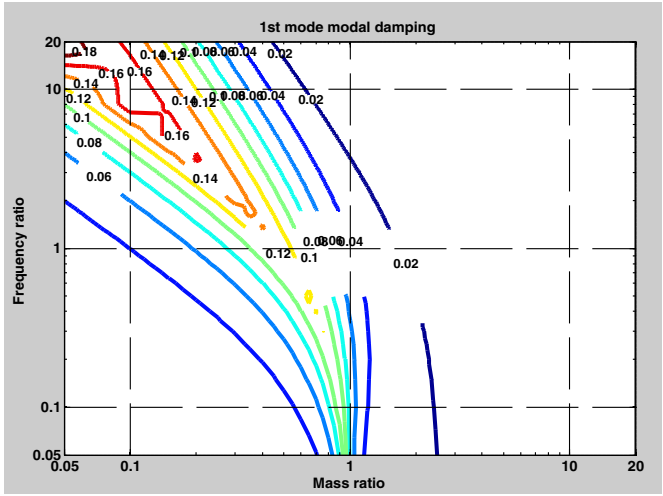

(d) $\zeta_{1}=0.02, \zeta_{2}=0.20$

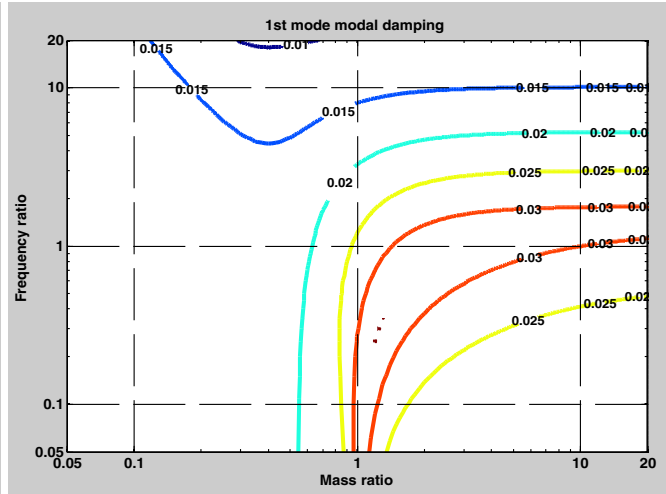

(c) $\zeta_{1}=0.05, \zeta_{2}=0.02$

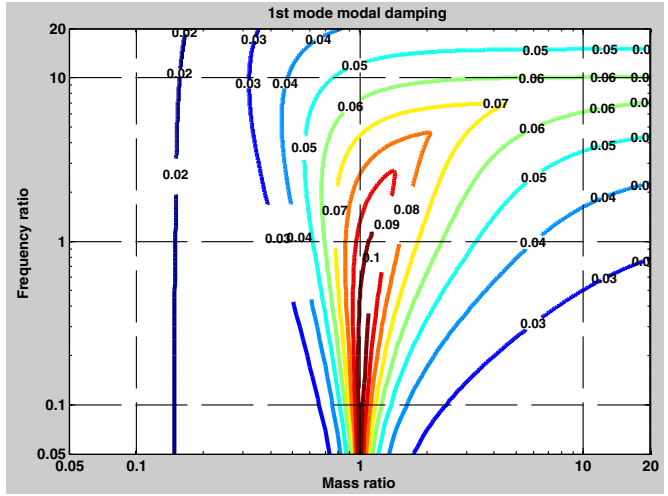

(e) $\zeta_{1}=0.20, \zeta_{2}=0.02$

Figure 5. $1^{\text {st }}$ mode modal damping variation with mass/frequency ratio. 
small as the system approaches regular mass distribution (mass ratio $=1.0)$, figure $4 \mathrm{a}$.

For a structural system with substructures of different material dampings, the damping behavior has two distinct trends: the first trend is shown in figure $4 \mathrm{~b}$ and $\mathrm{d}$, where substructure 2 has higher damping relative to that of substructure 1, the contour area for the case of uniform damping is stretched to lower value of frequency ratio, and the coupling index is characterized by a bell shape with high rate of change with mass ratio at low frequency ratio, the peak values increase as frequency ratio increases; the second trend is shown in figure $4 \mathrm{c}$ and $\mathrm{e}$, where substructure 1 has higher damping relative to that of substructure 2, The effect of mass ratio on coupling index has a bell shape with its peak locus shifts to a lower mass ratio and the peak value increases with the increase of the frequency ratio. For sub-systems with different dampings (non-classical damping scheme, super structure with damping $2 \%$, and sub-structure with higher damping 5\% and 20\%), a new trend behavior of the coupling index behavior with the variation of stiffness and mass irregularities of structure appears. For sub-structures with 5\% damping, the coupling index has two different regions, figure $4 \mathrm{c}$, the first trend is the same as that shown in figure $4 \mathrm{a}$, but this region becomes smaller. The second trend

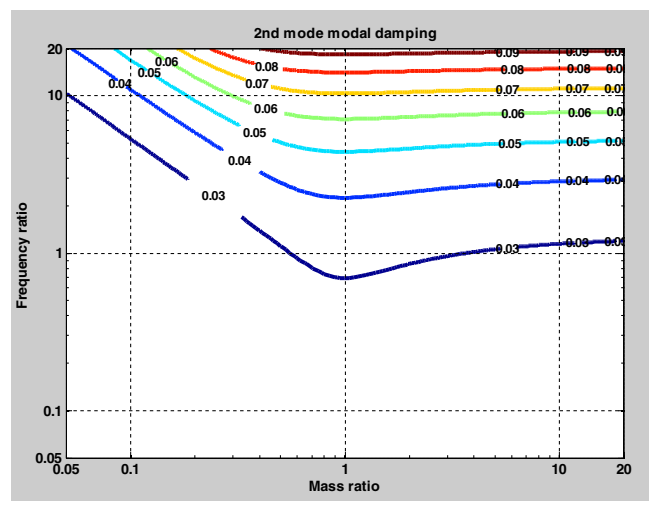

(a) $\zeta_{1}=\zeta_{2}=0.02$

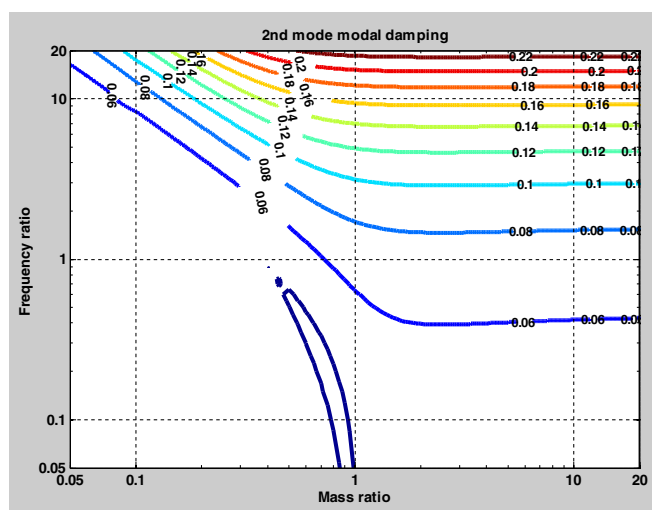

(b) $\zeta_{1}=0.02, \zeta_{2}=0.05$

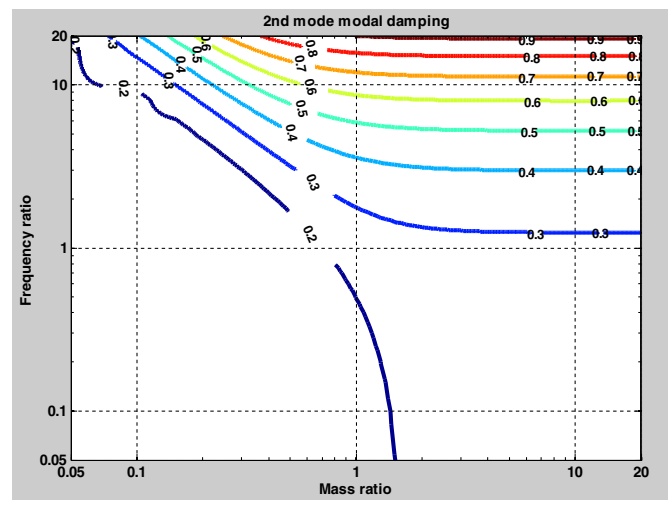

(d) $\zeta_{1}=0.02, \zeta_{2}=0.20$

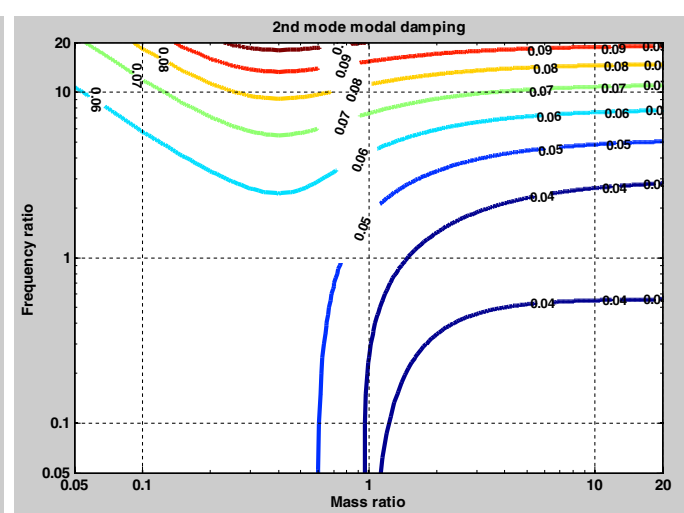

(c) $\zeta_{1}=0.05, \zeta_{2}=0.02$

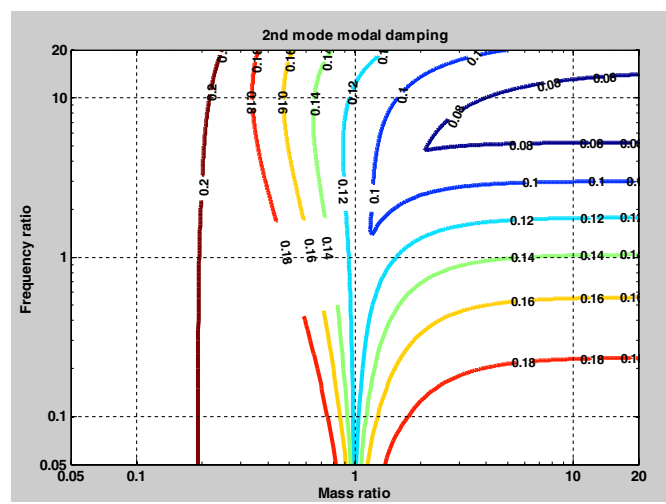

(e) $\zeta_{1}=0.20, \zeta_{2}=0.02$

Figure 6. 2nd mode modal damping variation with mass/frequency ratio. 


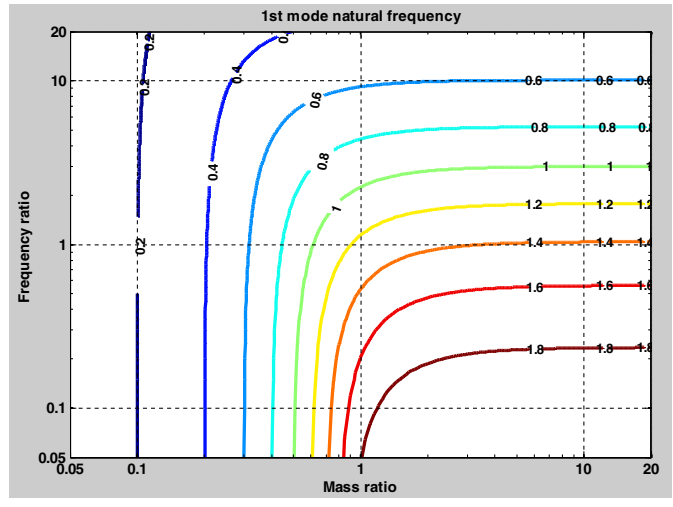

(a) $1^{\text {st }}$ mode of vibration

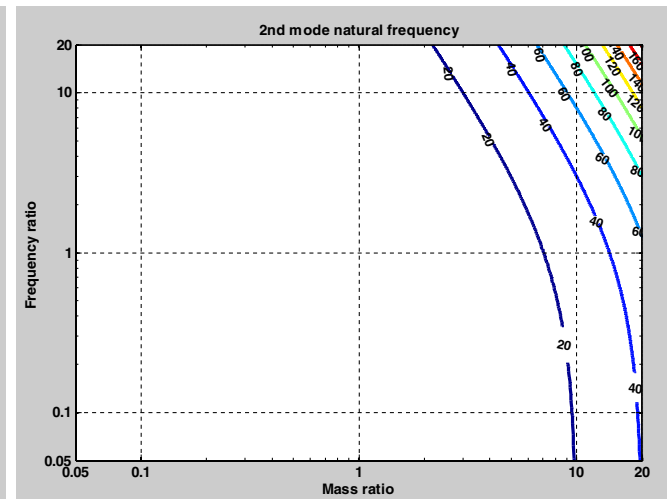

(b) $2^{\text {nd }}$ mode of vibration

Figure 7. Natural frequency variation with mass/frequency ratio $\left(\zeta_{1}=0.02 / 0.20, \zeta_{2}=0.02\right)$.

is that the coupling index increases with structure irregularities of mass and stiffness and, the peak locus makes a slight angle to the right with the vertical axis. As the frequency ratio increases, the coupling index decreases and expands over a wide range of mass ratio variations. The second region expands while the first region and trend disappear as shown in figure $4 \mathrm{e}$.

Figures 5 and 6 show the variation of the 1 st and the 2 nd mode modal damping with mass/frequency ratio, for subsystems with equal damping, the first mode modal damping decreases and the second mode modal damping increases with the increase of frequency ratio at constant level of mass ratio. At a certain level of frequency ratio, the first model modal damping decreases while the second model modal damping increases. This behavior gets its peaks around the uniform mass structure then keeps a constant horizontal trend "no effects". For sub-systems with different damping's (non-classical damping scheme, super structure with damping $2 \%$, and sub-structure with higher damping $5 \%$ and $20 \%$ ), a new trend behavior of the coupling index behavior with the variation of stiffness and mass irregularity of structure appears. For sub-structure with 5\% damping, modal have two different regions, figures $5 \mathrm{c}$ and $6 \mathrm{c}$, the first trend is the same as that shown in figures 5a and 6a, but this region gets smaller. The second trend is that the modal damping has bell shape with the variation of mass/frequency ratio. As frequency ratio increases, the modal damping expands over a wide range of mass ratio variation. The second region expands while the first region and trend disappear as shown in figure 5e and figure 6e. Figure 7 presents the natural frequency variation of 1 st and 2 nd vibration modes.

\subsection{Finite element model of hybrid tower structure}

A cable-stayed bridge located in Hokkaido, Japan is considered. Since cable-stayed bridges are not structurally homogeneous, the tower, deck and cable stays affect the structural response in a wide range of vibration modes. The tower is taken out of the cable-stayed bridge and modeled as three-dimensional frame structure as shown in figures 8 and 9. The dimensions units are based on SI system, meter; $\mathrm{m}$. The finite element model of the soil foundation superstructure interaction is formulated based on the design drawings [37-41]. Damping, which dissipates energy, as the velocities of motion and strain are varied, is important to dynamic structural analyses. The damping matrix for the complete system is constructed by directly assembling the damping matrices for the individual subsystems, assumed to be classically damped. Soil damping is captured primarily through the hysteretic energy dissipating response. Viscous damping, using the Rayleigh damping formulation, is often added to represent damping at very small strains where many soil models are primarily linear [38]. For concrete structures, the elastic damping ratio is taken as 5\% related to critical damping, a value that is supported by recent experiments [42].
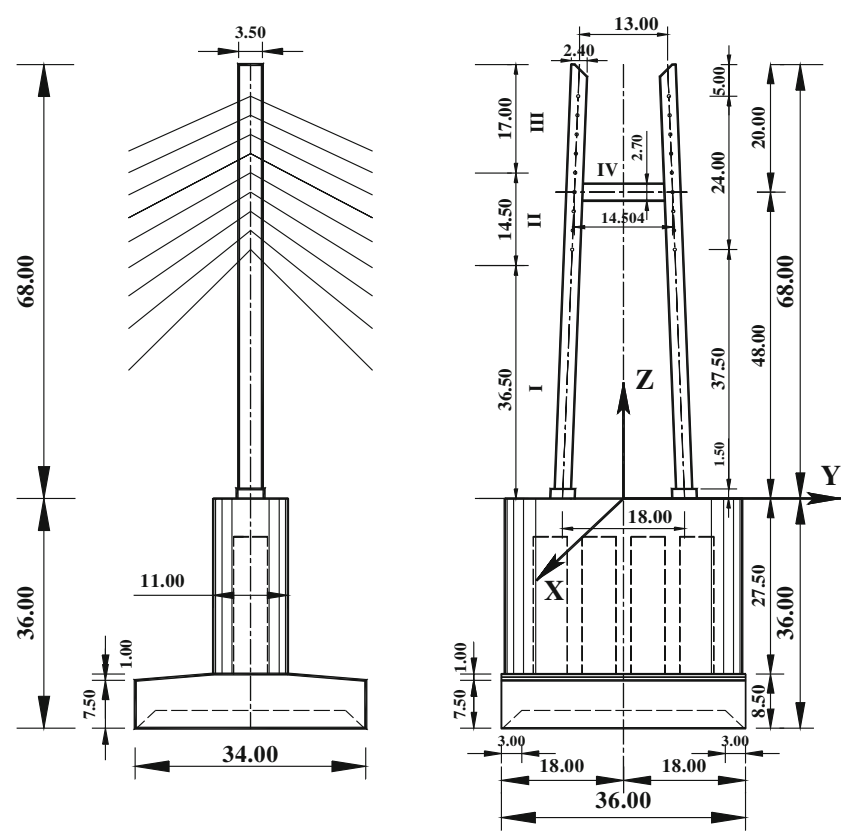

Figure 8. Tower structure of cable-stayed bridge $(m)$. 


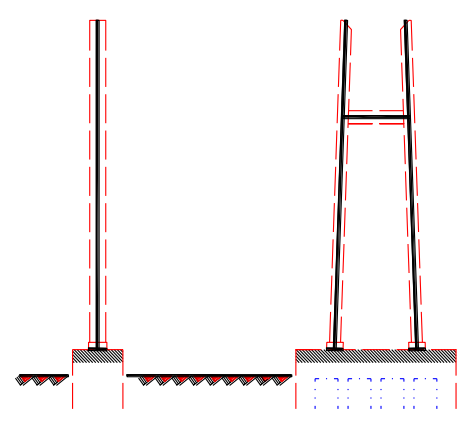

(a) Tower superstructure fixed base model

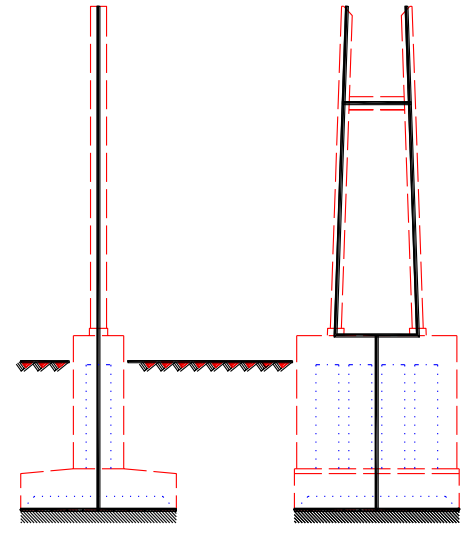

(b) Tower superstructure footing fixed base model

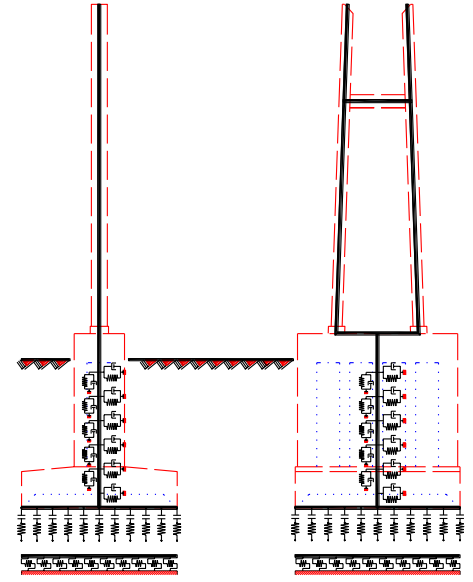

(c) Tower superstructure-footing soil interaction model

Figure 9. Different levels of finite element modeling for hybrid tower structure.

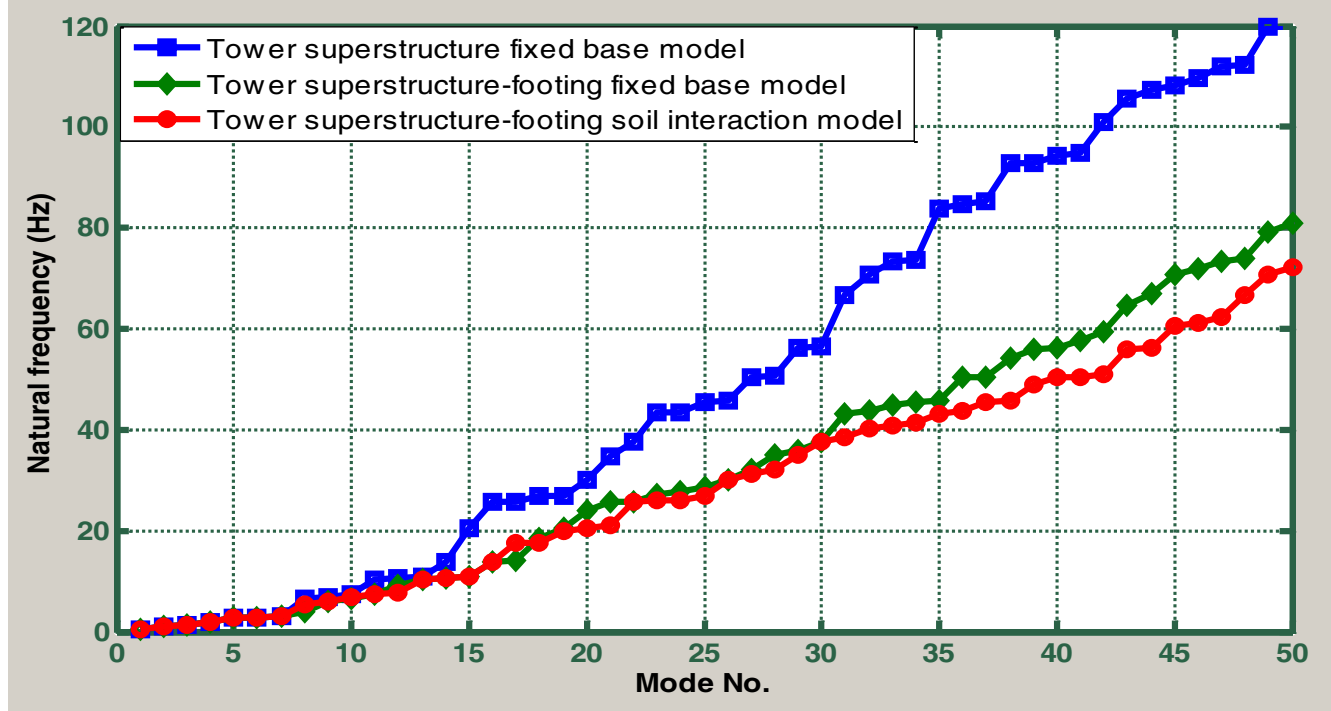

Figure 10. Natural frequencies for the first 35 Eigen modes of the different tower models.

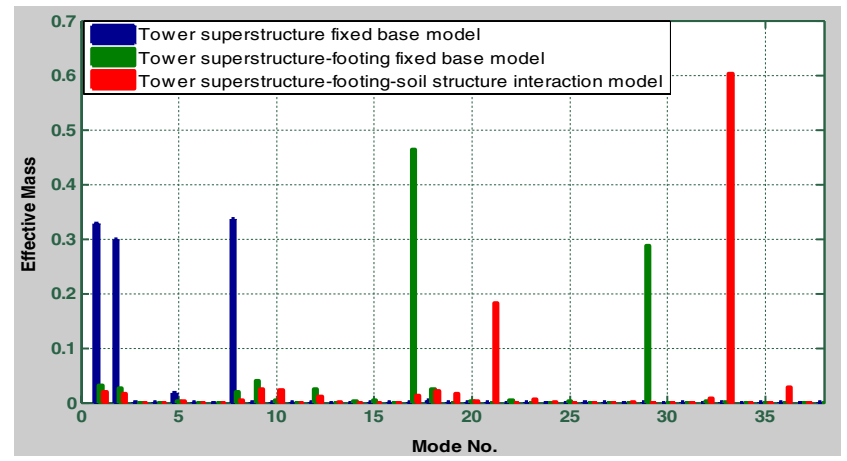

Figure 11. Modal effective mass ratio for the first 35 Eigen modes of the different tower models.

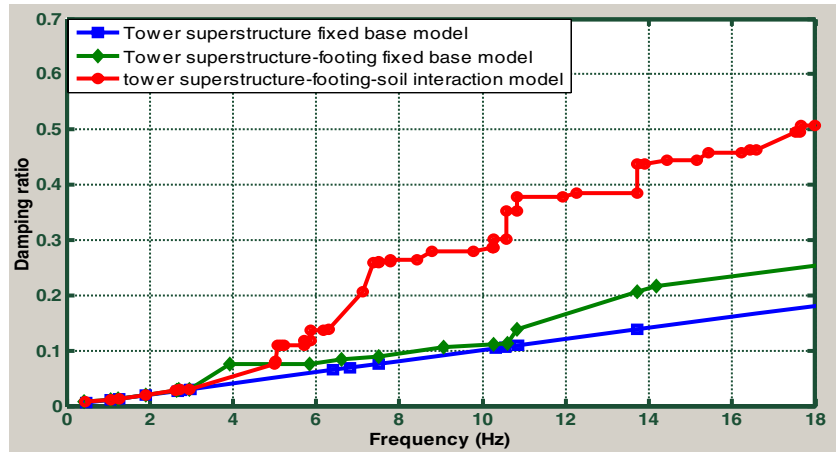

Figure 12. Modal damping ratio for different tower models. 
For cable stayed bridges without special dampers it can be assumed that the steel structural parts exhibit a uniformly distributed $2 \%$ viscous damping, and that the concrete parts exhibit a uniformly distributed 5\% damping, moreover, the Soil damping is captured primarily through the hysteretic energy using nonlinear soil springs for large strain of soil plus viscous damping using dashpot for small strain range of soil. Consequently, a pair of Rayleigh damping coefficients $a_{0 s}$ and $a_{1 s}$ can be used to describe the element damping matrices of all steel structural components. In addition another pair of Rayleigh damping coefficients $a_{0 f}$ and $a_{1 f}$ can be used to describe the element damping matrices of all concrete structural components. The damping matrices could be constructed by Rayleigh's damping procedures, thus the damping matrices for the structure and the foundation soil; $5 \%$ for the footing and $2 \%$ for the steel super-structure are used.

$$
\mathbf{c}_{s}=a_{0 s} \mathbf{m}_{s}+a_{1 s} \mathbf{k}_{s}, \quad \mathbf{c}_{f}=a_{0 f} \mathbf{m}_{f}+a_{1 f} \mathbf{k}_{f} .
$$

3.2a Vibration analysis hybrid tower model: Because the response of cable-stayed bridges significantly depends on the damping ratio, it is of great importance to correctly evaluate the damping ratio for seismic design. Therefore an analytical approach that is capable of evaluating the systemlevel damping based on the damping information of components is desirable. This approach is defined by dividing a cable-stayed bridge into several substructures. In this study, the damping characteristics soil foundation superstructure interaction model of cable-stayed bridges tower is studied. The formulation, analysis methods, and results are first compared for classically and non-classically damped structural systems. The effect of non-classical damping on the properties of natural frequency; vibration modes; effective modal mass and modal damping eigenvectors of soil foundation super-structure interaction model is presented and compared with that of fixed base model. From the un-damped natural vibration analysis, the dynamic characteristics including the natural frequency and the effective modal mass are investigated. Figure 10 shows the natural frequencies for the first 50 Eigen modes of the different tower models, the first seven modes up to $2.6 \mathrm{~Hz}$ almost coincide for the different models, while significant differences grow for higher modes due to footing and soil effects. The vibration modes of higher effective modal mass are significantly changed, which could be seen from figure 11. The type of modes of vibration would depend on relative stiffness and mass of different subsystems of tower structure. In the tower model of steel superstructure
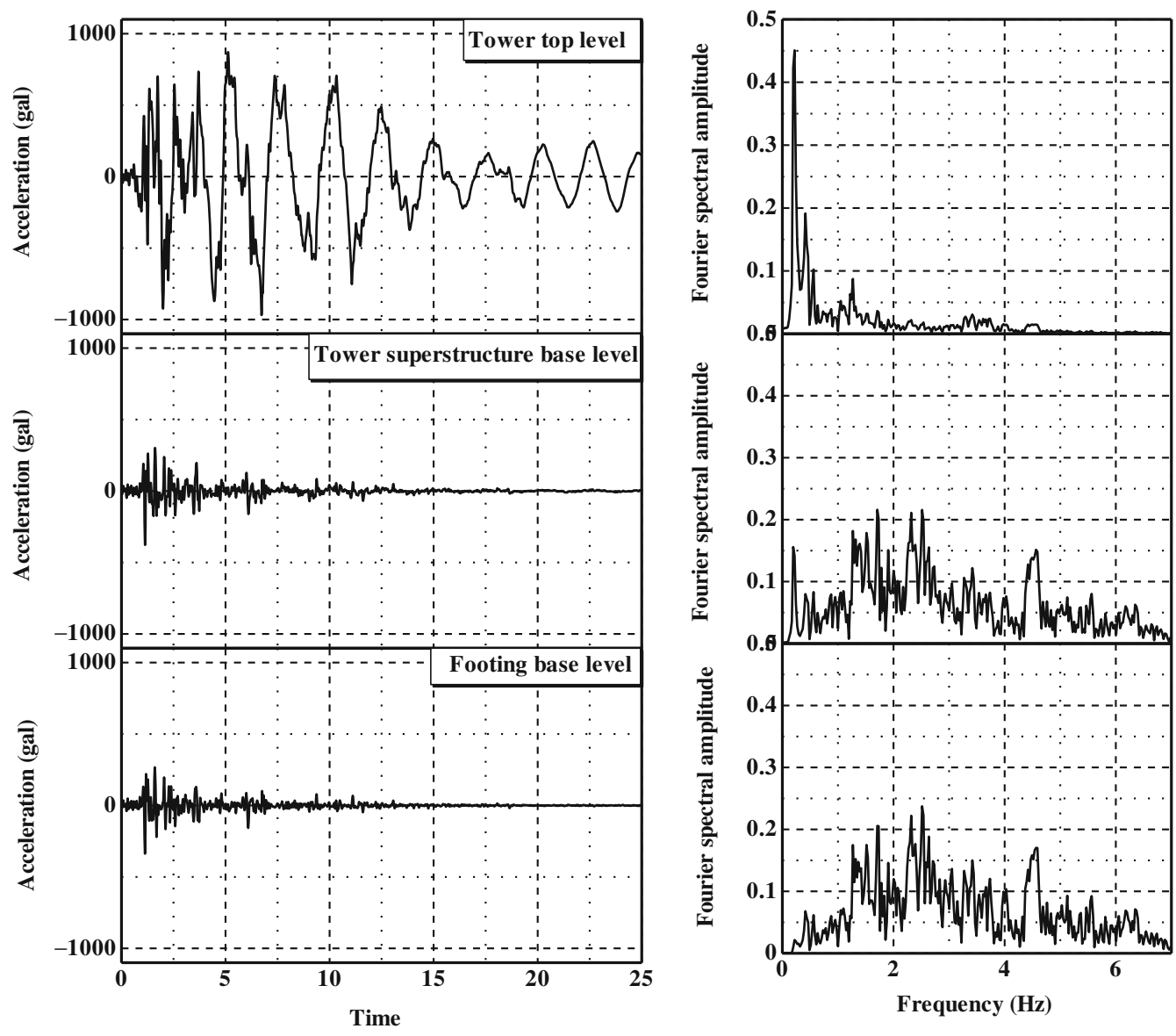

Figure 13. In-plane acceleration response time history and corresponding Fourier transform. 
that has classical damping characteristics, the modal damping has linear increase trend with natural frequency. While, in the composite towerfooting-soil interaction model that has non-classical damping characteristics, the modal damping has nonlinear increase trend with high rate compared to the fixed base model, and the higher modes get higher damping as shown in figure 12.

It is shown that in classically damped structures increasing the damping decreases the natural frequencies of the system; on the other hand, for non-classical damping structures some of the natural frequencies of the damped system may be greater than the corresponding natural frequencies of the un-damped system. Also the coupling index is calculated of the tower structure system, (it is equal to 0.174 and 0.349 for the tower footing fixed base model, and for the tower superstructure footing soil interaction model, respectively). The modal coupling could attribute different damping characteristics, dynamic (frequency ratio) and structural (mass and stiffness ratio) of the substructures of tower structure. Therefore, in the dynamic analysis of such structure, where the damping matrix is required for the complete system, more attention should be drawn in the formulation of damping matrix. Neglecting the non-classical damping effect would result in un-conservative results. The Rayleigh's damping can cause significant error in the calculation of the damping matrix if the combined structures have significant different substructure damping ratios.

\section{2b Nonlinear dynamic analysis hybrid tower model:} A nonlinear dynamic analysis, including soil-structure interaction, is developed to estimate the seismic response characteristics and to predict the earthquake response of cable-stayed bridges towers with spread foundation. An incremental iterative finite element technique is adopted for a more realistic dynamic analysis of nonlinear soilfoundation-superstructure interaction system under great earthquake ground motion. In the dynamic response analysis, the seismic motion by an inland direct strike type earthquake that was recorded during the 1995 HyogokenNanbu earthquake of high intensity but short duration is used as an input ground motion to assure the seismic safety of bridges. The horizontal and the vertical accelerations recorded at the station of JR-Takatori observatory are used for the dynamic response analysis of the cable-stayed bridge tower. From the Fourier spectra study of tower acceleration response at different levels of tower for soil foundation superstructure nonlinear interaction model, it is shown that there is an amplification of different modes over a wide frequency range as seen in figures 13 and 14.
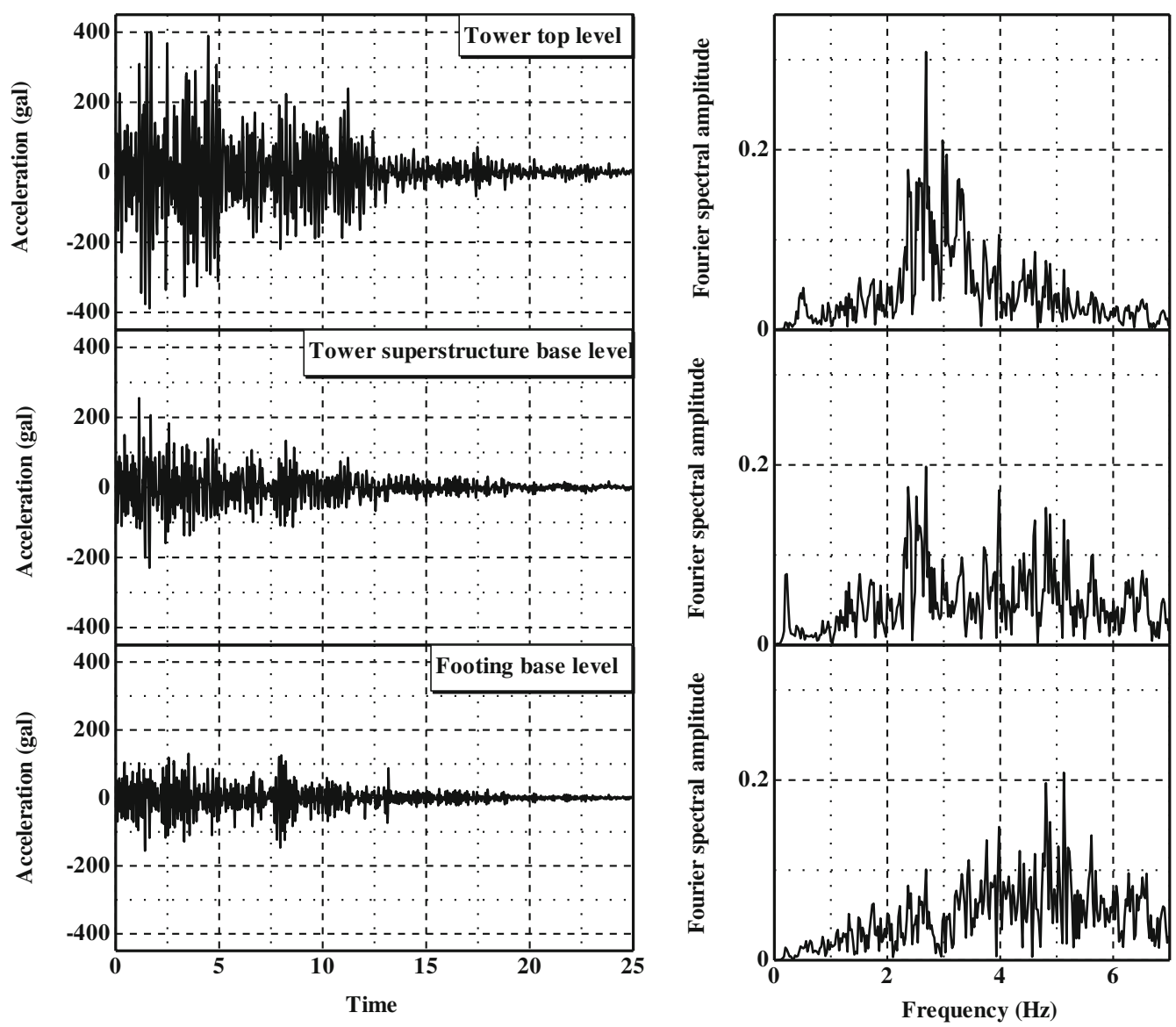

Figure 14. Vertical acceleration response time history and corresponding Fourier transform. 
The in-plane superstructure base response spectrum is larger than that at footing base at spectral frequency less than $2.0 \mathrm{~Hz}$ because of the amplification induced by the flexible superstructure and massive rigid substructure interaction, while at high frequencies above $2.0 \mathrm{~Hz}$, the response spectra are slightly attenuated due to inertial interaction. The tower top response spectra are significantly amplified at low frequency range and are almost totally attenuated at high frequency range due to tower superstructure flexibility. The massive foundation has the effect of amplifying the response over a wide frequency band. The vertical acceleration response at the footing base level shows relative high frequency amplification as the response spectra within the frequency range $2-3 \mathrm{~Hz}$ are slightly amplified at superstructure base level, and it is dramatically amplified at tower top. On the other hand, the response spectrum at high frequency range is attenuated by superstructure flexibility filter of the tower response. There is a great difference whether it is in vibration amplitude or in frequency property. The nonlinear properties of the foundations make the stiffness of the structure low, the response of rotational angle high and the bending moment response low.

\section{Conclusions}

The damping characterization is important in making accurate predictions of the seismic response of the hybrid structures dominated by different damping mechanisms. Different damping characteristics arise from the construction of the tower with different materials: steel for the upper part; reinforced concrete for the lower main part and interaction with supporting soil. In code-based seismic design of such structures several practical difficulties are encountered, due to inherent differences in the nature of the dynamic response of each part. Such structures are irregularly damped and have complex modes of vibration, so that their analysis cannot be handled with readily available commercial software. The specific issue addressed here is the analysis complications due to the different damping ratios of the different parts. Such structures are irregularly damped and have complex modes of vibration. In the dynamic analysis of a non-classically damped and coupled system, such soil structure interaction systems, a major step is to define and compute the damping matrix for the combined system either in the time domain or the modal domain. The task of computing the damping matrix for the coupled system is a nontrivial process especially when the components within the system have large dissimilar damping characteristics and are dominated by different energy dissipation mechanisms. The formulation, analysis methods and results have been compared in this paper for classically and non-classically damped structural systems. The following conclusions can be drawn from this study:

- The un-damped modal vectors to be coupled with respect to the damping matrix. The proportional modal damping can result in incorrect responses in nonclassically damped systems.

- The choice of a proper damping ratio and formulation of damping matrix are critical to the design/analysis of hybrid tower structure response, the damping of the hybrid system exhibits non-classical damping that gives rise to complex-valued mode shapes.

- The Rayleigh's damping can cause significant errors in the calculation of the damping matrix if the hybrid structures have significant different substructure damping ratios.

- A complication of large damping arises when natural frequencies are close, which is a common situation for high frequency modes in complex systems. In such situations, the modal bandwidth of adjacent resonant peaks might exceed the natural frequency difference, leading to a merger of the resonant peaks into one broader peak, which is known as mode coupling. This can make it difficult to distinguish between the individual modes.

- The effect of non-classical damping is significant in systems that have nearly tuned modes and sufficiently small values of modal mass ratios.

- For systems with non-classical damping distributions, the phase angles generally lie between zero and 180 degrees and thus the DOF's are either in-phase or completely out-of-phase. The result is that the shape of the free vibration response in a given mode shape changes with time. For the non-classical damped system, the damping affects the slope of the phase and the amplitude of the peak response.

- As the mass ratio decreases, the vibration modes get closer, the soft substructure dominant frequency increases, while the stiff substructure dominant frequency decreases. The lower mass ratio leads to significant modal coupling especially for equal dominant frequencies of substructures. Also a horizontal shift in the position of the natural frequencies is noted as the mass ratio increases.

\section{References}

[1] Johnson C D and Kienhholz D A 1982 Finite element prediction of damping in structures. Am. Inst. Aeronaut. Astronaut. J. 20(9): 1284-1290

[2] Kawashima K, Unjoh S and Tunomoto M 1993 Estimation of damping ratio of cable-stayed bridges for seismic design. J. Struct. Eng. 119(4): 1015-1031, doi:10.1061/(ASCE)07339445(1993)119:4(1015)

[3] Huang B C, Leung A Y T, Lam K M and Cheung Y K 1995 Analytical determination of equivalent modal damping ratios of a composite tower in wind-induced vibrations. Comput. Struct. 59(2): 311-316, doi: 10.1016/0045-7949(95)00258-8

[4] Casciati F, Cimellaro G P and Domaneschi M 2008 Seismic reliability of a cable-stayed bridge retrofitted with 
hysteretic devices. Comput. Struct. 86(17-18): 1769-1781, doi: 10.1016/j.compstruc.2008.01.012

[5] Abdel Raheem S E and Hayashikawa T 2007 Damping characteristics in soil-foundation-superstructure interaction model of cable-stayed bridges tower. J. Construct. Steel Japanese Soc. Steel Construct. 15: 261-268

[6] Abdel Raheem S E and Hayashikawa T 2008 Vibration and damping characteristics of cable-stayed bridges tower. International Association for Bridge and Structural Engineering IABSE Conference, Information and Communication Technology (ICT) for Bridges, Buildings and Construction Practice, Helsinki, Finland, June 4-6, 2008, Paper ID. F15

[7] Lee S, Feng M Q, Kwon S-J and Hong S-H 2011 Equivalent modal damping of short-span bridges subjected to strong motion. J. Bridge Eng. 16(2): 316-323, doi:10.1061/(ASCE) BE.1943-5592.0000149

[8] Cimellaro G P, Soong T T and Reinhorn A M 2009 Integrated design of controlled linear structural systems. J. Struct. Eng. ASCE 135(7): 853-862, doi:10.1061/(ASCE)ST.1943-541X. 0000032

[9] Soong T T and Cimellaro G P 2009 Future directions on structural control. J. Struct. Control Health Monitoring 16(1): 716, doi: 10.1002/stc.291

[10] Abdel Raheem S E, Hayashikawa T and Dorka U 2009 Seismic performance of cable-stayed bridge towers: nonlinear dynamic analysis, structural control and seismic design. VDM Verlag, ISBN: 978-3639202236

[11] Prater G and Singh R 1990 Eigenproblem formulation, solution and interpretation for non-proportionally damped continuous beams. J. Sound Vibr. 143(1): 125-42, doi:10.1016/0022460X(90)90572-H

[12] Prells U and Friswell M I 2000 A measure of non-proportional damping. Mech. Syst. Signal Process. 14(2): 125-137, doi: 10.1006/mssp. 1999.1280

[13] Angeles J and Ostrovskaya S 2002 The proportional damping matrix of arbitrarily damped linear mechanical systems. $J$. Appl. Mech. 69: 649-656, doi: 10.1115/1.1483832

[14] Du Y, Li H and Spencer B F 2002 Effect of non-proportional damping on seismic isolation. J. Struct. Control 9: 205-236, doi: $10.1002 /$ stc. 13

[15] Adhikari A 2004 Optimal complex modes and an index of damping non-proportionality. Mech. Syst. Signal Process. 18: 1-27, doi: 10.1016/S0888-3270(03)00048-7

[16] Xu J, DeGrassi G and Chokshi N 2004a A NRC-BNL benchmark evaluation of seismic analysis methods for nonclassically damped coupled systems. Nucl. Eng. Des. 228: 345-366, doi: 10.1016/j.nucengdes.2003.06.019

[17] Xu J, DeGrassi G and Chokshi N 2004b Insights Gleaned from NRC-BNL benchmark evaluation of seismic analysis methods for non-classically damped coupled systems. $J$. Pressure Vessel Technol. 126: 75-84, doi: 10.1115/1.1638388

[18] Khanlari K and Ghafory-Ashtiany M 2005 New approaches for non-classically damped system Eigen analysis. Earthq. Eng. Struct. Eng. 34: 1073-1087, doi: 10.1002/eqe.467

[19] Qu Z-Q, Selvam R P and Jung Y 2003 Model condensation for non-classically damped systems-part ii: Iterative schemes for dynamic condensation. Mech. Syst. Signal Process. 17(5): 1017-1032, doi: 10.1006/mssp.2002.1527

[20] Bert C W 1973 Material damping: an introductory review of mathematical models, measure and experimental techniques. J. Sound Vibr. 29(2): 129-153
[21] Bread C F 1979 Damping in structural joints. J. Shock Vibr. Digest 11(9): 35-41

[22] Chang S-Y 2013 Nonlinear performance of classical damping. Earthq. Eng. Eng. Vibr. 12: 279-296

[23] Chopra A K 1995 Dynamic of structures - theory and application to earthquake engineering. Prentice-Hall, Englewood Cliffs, NJ

[24] Ding N H, Lin L X and Chen J D 2011 Seismic response analysis of double chains suspension bridge considering nonclassical damping. Adv. Mater. Res., 255-260, 826-830, doi: 10.4028/AMR.255-260.826

[25] Raggett J D 1975 Estimation of damping of real structures. $J$. Struct. Div. ASCE 101(ST9): 1823-1835

[26] Lee S-H, Min K-W, Hwang J-S and Kim J 2004 Evaluation of equivalent damping ratio of a structure with added dampers. Eng. Struct. 26: 335-346, doi:10.1016/j.engstruct.2003.09.014

[27] Papageorgiou A V and Gantes C J 2010 Equivalent modal damping ratios for concrete/steel mixed structures. Comput. Struct. 88(19-20): 1124-1136, doi:10.1016/j.compstruc.2010. 06.014

[28] Papageorgiou A V and Gantes C J 2011 Equivalent uniform damping ratios for linear irregularly damped concrete/steel mixed structures. Soil Dynamic Earthq. Eng. 31(3): 418-430, doi: 10.1016/j.soildyn.2010.09.010

[29] Villaverde R 2008 A complex modal superposition method for the seismic analysis of structures with supplemental dampers. 14th world conference on earthquake engineering, 14WCEE, Beijing, China

[30] Warburton G B and Soni S R 1977 Errors in response calculations for non-classically damped structures. Earthq. Eng. Struct. Dyn. 5: 365-376, doi: 10.1002/eqe.4290050404

[31] Qin Q and Lou L 2000 Effects of non proportional damping on the seismic responses of suspension bridges. 12th world conference of earthquake engineering, Auckland, New Zealand, 30 January - 4 February 2000, paper No. 0529

[32] Japan Road Association 1996 Reference for highway bridge design, Specification for highway bridges-part IV substructures. Chapter 7-9

[33] Japan Road Association 2002 Specification for highway bridges-Part V Seismic design. Maruzen, Tokyo, Japan

[34] Claret A M and Venancio-Filho F 1991 A modal superposition method pseudo-force method for dynamic analysis of structural systems with non-proportional damping. Earthq. Eng. Struct. Eng. 20: 303-315, doi: 10.1002/eqe.4290200402

[35] Falsone G and Muscolino G 2004 "New real-value modal combination rules for non-classically damped structures. Earthq. Eng. Struct. Eng. 33: 1187-1209, doi:10.1002/eqe.394

[36] Veletsos A S and Ventura C E 1986 Model analysis of nonclassically damped linear systems. Earthq. Eng. Struct. Dyn. 14: 217-243, doi: 10.1002/eqe.4290140205

[37] Abdel Raheem S E, Hayashikawa T and Hashimoto I 2003 Effects of soil-foundation-superstructure interaction on seismic response of cable-stayed bridges tower with spread footing foundation. J. Struct. Eng. - JSCE 49A: 475-486

[38] Park D and Hashash Y M A 2004 Soil damping formulation in nonlinear time domain site response analysis. J. Earthq. Eng. 8(2): 249-274, doi: 10.1080/13632460409350489

[39] Hayashikawa T, Abdel Raheem S E and Hashimoto I 2004 Nonlinear seismic response of soil-foundation-structure interaction model of cable-stayed bridges tower. 13th World Conference on Earthquake Engineering, Vancouver, Canada, 1-6 August, Paper No. 3045 
[40] Abdel Raheem S E and Hayashikawa T 2013a Energy dissipation system for earthquake protection of cable-stayed bridge towers. Int. Earthquakes Structures, Techno-Press publishers 5(2): 657-678, doi: 10.12989/eas.2013.5.6.657

[41] Abdel Raheem S E and Hayashikawa T 2013b Soilstructure interaction modeling effects on seismic response of a cable-stayed bridge tower. Int. J. Adv. Struct. Eng. 5(8): 1-17, doi: 10.1186/2008-6695-5-8

[42] Petrini L, Maggi C, Priestley M J N and Calvi G M 2008 Experimental verification of viscous damping modelling for inelastic time history analyses. J. Earthq. Eng. 12(SP1): 125145, doi: 10.1080/13632460801925822 